\title{
Rethinking Origin Essentialism (for artefacts)
}

Abstract. The thesis that the material origins of artefacts are essential to them is highly intuitive, but in a flexible version. It is not exact match of material origins that is intuitively essential, but approximate match. After an in-depth exploration of the theoretical options open to accommodate the flexible version, the paper ends up favouring the inflexible one.

Keywords: Essentiality of Origin, S4, sufficiency properties, coincidents, individual essences 


\section{Rethinking Origin Essentialism (for artefacts)}

\section{Introduction}

The thesis of essentiality of origins-roughly, that origins are essential to originated entities-has been wildly discussed in the literature. Although not universally accepted, ${ }^{1}$ it is the majority's view that some qualified and perhaps restricted version of it is true. There is no consensus, however, as to which is the strongest, true version. ${ }^{2}$ Part of the controversy turns on what should be considered as partly constitutive of an entity's origin. When restricted to artefacts, for instance, the material aspect seems relevant, as well as authorship, but not so much the location aspect. We can capture the relevance of the material aspect by means of a qualified version of essentiality of origins, restricted to artefacts, which I shall call 'Essentiality of Material Origins for Artefacts'; (EMOA) for short. (EMOA) holds that material origins are essential to artefacts. Not even this qualified and restricted version, however, is free of controversy. Intuition seems to call for further relaxation. Let $a$ be a table actually originated from matter $\mathrm{m}_{0}$. Intuitively, if, at the moment of creation, a single molecule of $\mathrm{m}_{0}$ had been absent or replaced by another, $a$ would still have come into existence. Accordingly, it is not exact match of material origins that is intuitively relevant to the identity of table $a$ but, rather, approximate match. We can thus distinguish between an inflexible and a flexible version of (EMOA). Consider the inflexible property $\mathrm{F}_{0}$ and the flexible $\mathscr{F}_{0}$ :

$\mathrm{F}_{0}$ : being originally constructed from (exactly) $\mathrm{m}_{0}$

$\mathscr{F}_{0}$ : being originally constructed from a hunk of matter that highly overlaps with $\mathrm{m}_{0}$

Whereas inflexible-(EMOA) holds that $\mathrm{F}_{0}$ is essential to $a$, flexible-(EMOA) holds that it is $\mathscr{F}_{0}$. According to inflexible-(EMOA), there is only one piece of matter table $a$ can be made from: $\mathrm{m}_{0}$. By contrast, according to flexible-(EMOA), there are several hunks $a$ could be made from. For simplicity, I shall assume all along the paper that, according to flexible(EMOA), there are always (exactly) 5 pieces of matter a very same table could be made from. In the case of $a$, let these hunks be: $\mathrm{m}_{-2}, \mathrm{~m}_{-1}, \mathrm{~m}_{0}, \mathrm{~m}_{1}$ and $\mathrm{m}_{2}{ }^{3}$ With this assumption, $\mathscr{F}_{0}$ can be extensionally analysed as the property of being originally constructed from $m_{-2}$, $m_{-1}, m_{0}, m_{1}$ or $m_{2}$. (I shall treat this property and $\mathscr{F}_{0}$ as the same property; nothing essential depends on it.)

As mentioned above, flexible-(EMOA) is intuitively more plausible: the very same table could intuitively have originated from slightly different pieces of matter. This much is widely accepted. The reason why flexible-(EMOA) is nonetheless a controversial thesis is that endorsing it has been proved to have costs somewhere else in one's philosophical system. Salmon (1982), for instance, thinks that endorsing it—as he thinks

\footnotetext{
${ }^{1}$ Strong haecceitists, like P. Mackie (2006), for instance, would reject it.

2 See footnote 7 for some sample literature.

3 The property $\mathrm{F}_{0}$ implies the flexible one $\mathscr{F}_{0}$ : whatever comes from $\mathrm{m}_{0}$ comes from either $\mathrm{m}_{-2}$, $\mathrm{m}_{-1}, \mathrm{~m}_{0}, \mathrm{~m}_{1}$ or $\mathrm{m}_{2}$. Yet, the essentialist claim ' $\mathrm{F}_{0}$ is essential to $a$ ' does not imply the claim ' $\mathscr{F}_{0}$ is essential to $a$ '. The former implies that a must originate from $\mathrm{m}_{0}$, whereas the latter implies that $a$ can originate from any of $\mathrm{m}_{-2}, \mathrm{~m}_{-1}, \mathrm{~m}_{0}, \mathrm{~m}_{1}$ or $\mathrm{m}_{2}$ (and must originate from one of those).
} 
one should do-forces us to reject that the accessibility relation among worlds is transitive. This is a cost for everyone. Simplicity and elegance (if not (also) intuitive) considerations favour the transitivity of that relation over its non-transitivity. It is a cost that, while Salmon is ready to pay, Williamson (1990) is not. As a reaction, and against Salmon, Williamson shows that one can have both desiderata: one can accommodate the transitivity of the accessibility relation among worlds within a flexible-(EMOA) framework. Unfortunately, however, Williamson's solution is not as stable as one would think on this basis, for it has other costs; costs that Salmons' account does not have. Namely, Williamson's solution is in conflict with the thesis that there are no coincident artefacts of the same kind, fully sharing their spatio-temporal region, thereby allowing, contra intuition, the existence of several fully spatio-temporally coincident tables.

One aim of this paper is to scrutinize Salmon's and Williamson's views to see whether we can find reasons to prefer one to the other. On the basis of what this introduction has made explicit so far, we seem to be facing a reflective equilibrium problem involving three main theses:

(1) Flexible-(EMOA)

(2) The accessibility relation among worlds is transitive

(3) There are no coincident artefacts of the same kind, fully sharing their spatiotemporal region

There also seems to be a tie between the two views: each manages to accommodate exactly two of the three desiderata theses. To be able to break the (apparent) tie, the scrutinizing of the views should reveal additional hidden costs in at least one of the views. As it will turn out, there are two further desiderata-theses that only Williamson's view manages to accommodate. This will be offered as reasons to prefer it to Salmon's:

(4) There are sufficient conditions for the existence of artefacts

(5) If $\mathrm{P}$ is the individual essence of an artefact, then all properties analogous to $\mathrm{P}$ are individual essences of artefacts too

All five theses will end up being involved in the reflective equilibrium exercise this paper constitutes. The game is to find the most conservative view. It is a sub-optimal game right from the start because, on the one hand, (1)-(5) are jointly incompatible 4 and, on the other, each is, individually, a desiderata: flexible-(EMOA) is (intuitively) preferable to both its inflexible version and the denial of the essentiality of origins altogether, and each of (2)-(5) is preferable-either theoretically, intuitively, or bothto its negation. So there will be a cost somewhere; the aim is to minimize it.

An initial diagnosis, as anticipated, is that Williamson's view is superior to Salmon's in that while Williamson's accommodates all theses except (3)-this is shown in §3Salmon's accommodates only (1) and (3); as shown in $§ 2$. Despite this superiority, denying (3) might be unacceptable in itself. At this point, and as a second aim of the paper, the exploration of a view that denies only (1) - and endorses instead inflexible(EMOA) as the most conservative way of denying (1)-emerges as an urgent task; one that I take up in $\S 4$. This exploration has been neglected in the literature on the basis of the intuitiveness of flexible-(EMOA) - and the unintuitiveness of inflexible-(EMOA). It is

\footnotetext{
${ }^{4}$ It is not convenient to unfold the incompatibility without appropriate stock, but the incompatibility will emerge clear as we go along and it is shown in footnote 18.
} 
not to be taken for granted, however, that a view that denies (1) will always be, all things considered, a loser; I shall motivate that it is not.

\section{Scrutinizing Salmon's view}

On the basis of flexible-(EMOA) - our thesis (1)-Salmon (1982) constructs a paradox, the Four worlds paradox, and suggests as a (forced upon) solution to it the nontransitivity of the accessibility relation among worlds-that is, the denial of (2). The paradox is initially presented as a conflict between (1) and (4) but, according to Salmon, his solution allows him to diagnose that conflict as merely apparent and to keep both of them. Before presenting the paradox, we should see what thesis (4) amounts to and how it interacts with (1).

Preliminaries. Essential properties typically impose necessary conditions for entities to exist: if property $\mathrm{F}_{0}$ is essential to $a$, table $a$ cannot exist unless it originates from (exactly) $\mathrm{m}_{0}$. If it is instead the flexible $\mathscr{F}_{0}$ that is essential to $a$, $a$ cannot exist unless it originates from some of $\mathrm{m}_{-2}, \mathrm{~m}_{-1}, \mathrm{~m}_{0}, \mathrm{~m}_{1}$ or $\mathrm{m}_{2}$. The literature has also flirted with sufficiency properties: properties that provide instead sufficient conditions for the existence of entities.

Take table $a$ again. Apart from the material aspect of its origin, $\mathrm{m}_{0}$, let's take into account also the artisan who made it, $A$, the manufacturing plan, $P$, and the time and place of the manufacturing process, $t$ and $p$. Salmon believes that instantiation of the following complex property is sufficient for table $a$ (and no other) to pop into existence:

$\mathrm{S}_{0}=$ being originally made from $\mathrm{m}_{0}$, by $A$, according to $P$, and at $t$ and $p$.

Salmon is therefore committed to (4) by means of endorsing properties like $S_{0}$ as sufficiency properties; equivalently, by means of endorsing trans-world identification principles like (V"): ${ }^{5}$

$\left(V^{\prime \prime}\right)$ If it is possible for a table $x$ to be the only table [in a world] originally constructed (by a certain artisan in a certain place at a certain time) from a certain hunk of matter $y$ according to plan $P$, then necessarily, any table that is the only table [in a world] to be originally constructed (by the very same artisan in the very same place at the very same time) from the very same hunk of matter $y$ according to the very same plan $P$ is the very same table $x$ and no other. (Salmon 1982, 229) ${ }^{6}$

The intuition behind sufficiency principles like (V") is known in the literature as an antihaecceitist intuition, which would be contrary to haecceitistic switches among worlds; that is, contrary to the existence of atom-per-atom identical worlds that nonetheless differ in which individuals exist in them. These are the sort of questions one can motivate the anti-haecceitist intuition with:

\footnotetext{
5 I am keeping Salmon's name.

${ }^{6}$ Sufficiency properties provide trans-world identification principles because it is impossible for two worlds to agree on which sufficiency properties are instantiated and yet disagree on which entities instantiate them. They serve to identify the instantiator of, say, $\mathrm{S}_{0}$, in one world as (numerically) the same entity as that which instantiates $\mathrm{S}_{0}$ in another world.
} 
If two tables in two different possible worlds are constructed from the very same stuff in precisely the same way and, let us assume, with exactly the same structure atom from atom, how can they fail to be the very same table? What more could one ask? What more is there to being this very table? (Salmon 1982, p. 211)

The intuition underlying (4) is, thus, that being supervenes on qualitative character and identity of matter (if not on qualitative character alone).

Salmon's belief in sufficiency properties such as $\mathrm{S}_{0}$ combined with his belief in flexible(EMOA) commits him, first, to $S_{0}$ not being essential to $a$ and, second, to it not being the only property that is sufficient for $a$ 's existence. It is not essential to $a$ because, according to flexible-(EMOA), a can equally come into existence from $\mathrm{m}_{-2}, \mathrm{~m}_{-1}, \mathrm{~m}_{1}$ or $\mathrm{m}_{2}$. It is not the only sufficiency property for $a$ because, given ( $\left.\mathrm{V}^{\prime \prime}\right)$ and $a^{\prime}$ 's five possible material origins, these other properties are also sufficient for $a$ 's existence:

$$
\begin{aligned}
& \mathrm{S}_{-2}=\text { being originally made from } m_{-2} \text {, by } A \text {, according to } P \text {, and at } t \text { and } p \\
& \mathrm{~S}_{-1}=\text { being originally made from } m_{-1} \text {, by } A \text {, according to } P \text {, and at } t \text { and } p \\
& \mathrm{~S}_{1}=\text { being originally made from } m_{1} \text {, by } A \text {, according to } P \text {, and at } t \text { and } p \\
& \mathrm{~S}_{2}=\text { being originally made from } m_{2} \text {, by } A \text {, according to } P \text {, and at } t \text { and } p
\end{aligned}
$$

So far, therefore, $a$ has an essential property-the flexible $\mathscr{F}_{0}$-and five sufficiency properties-the inflexible $\mathrm{S}_{-2}, \mathrm{~S}_{-1}, \mathrm{~S}_{0}, \mathrm{~S}_{1}$ and $\mathrm{S}_{2}$. It also has an individual essence. An individual essence is a property, $\mathrm{P}$, which is both essential to an entity and sufficient for its existence. Individual essences, therefore, provide both necessary and sufficient conditions for the existence of entities. None of the properties considered so far, however, are candidates to being individual essences of $a$. For none of the sufficiency properties above is in addition essential to $a$, and $\mathscr{F}_{0}$ is arguably not in addition a sufficiency property of $a$; for $\mathrm{m}_{0}$ could be used to make different types of entities, or a largely different table by someone else. This is not to say, however, that Salmon is notby endorsing both (1) and (4)-committed to individual essences as well. He is. The current considerations help us reveal that $a^{\prime}$ s individual essence is of a flexible sort, because it inherits $\mathscr{F}_{0}$ 's flexibility. To illustrate this we've got to simplify or the discussion will soon become unmanageable. From now on, let us abbreviate with ' $\mathrm{C}$ ' the artisan, plan, time and place parameters above, and let us assume that $\mathrm{S}_{-2}, \mathrm{~S}_{-1}, \mathrm{~S}_{0}, \mathrm{~S}_{1}$ and $\mathrm{S}_{2}$ are the only possible ways for $a$ to come into existence. ${ }^{7}$ With this abbreviation and simplification, the flexible $\mathcal{S}_{0}$ is an individual essence of $a$ :

$S_{0}=$ Originating from any of $\mathrm{m}_{-2}, \mathrm{~m}_{-1}, \mathrm{~m}_{0}, \mathrm{~m}_{1}$ and $\mathrm{m}_{2}$ plus the C-conditions.

That $\mathcal{S}_{0}$ is, despite flexible, an individual essence of $a$ is grounded in that originating from some of $m_{-2}$ to $m_{2}$ (plus $\mathrm{C}$ ) is necessary for $a^{\prime}$ 's existence while originating from any of them (plus C) is sufficient for it. These preliminaries put us in a position to see next the apparent conflict between (1) and (4) which generates the paradox.

\footnotetext{
7 This assumes that all the C-parameters are inflexibly essential to $a$. This is harmless idealization. There is a discussion on C-constraints led by Robertson (1998 and 2000), Forbes (2002) and Hawthorne and Gendler (2000). I sympathize with most of Robertson's ideas but nothing here requires me to engage in that (orthogonal) discussion: whatever the C-constraints are, they belong to what I am here abbreviating with ' $C$ ' and assuming to be inflexibly essential.
} 
The Four Worlds Paradox. Assume flexible-(EMOA) - thesis (1)-and assume also that the maximum difference a table can allow in its origins is $2 \%$ of its original matter. Let $\mathrm{w}_{1}$ be the actual world where a table, $a$, is originally constructed from $\mathrm{m}_{0}$ (plus C). From $\mathrm{w}_{1}$, it is possible to make some table from $\mathrm{m}_{3}, 3 \%$ different from $\mathrm{m}_{0}$. Let $\mathrm{w}_{2}$ account for this possibility. By flexible-(EMOA) plus the $2 \%$ assumption, we get that $a$ is numerically distinct from $b$. However, again by flexible-(EMOA), both $a$ and $b$ could originate from $\mathrm{m}_{2}$ (plus $\mathrm{C}$ ), where $\mathrm{m}_{2}$ is $2 \%$ different from $\mathrm{m}_{0}$ and $1 \%$ different from $\mathrm{m}_{3}$. This gives us two further worlds, $\mathrm{w}_{3}$ and $\mathrm{w}_{4}$, accounting for these possibilities. Schematically:

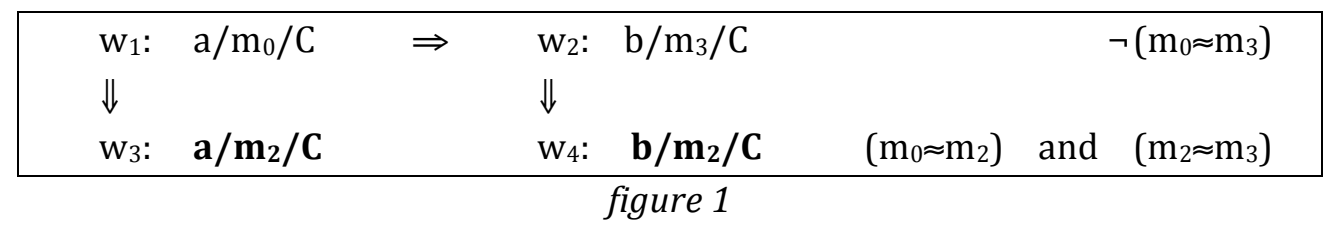

Notation: $\ulcorner\mathrm{X} \approx \mathrm{y}\urcorner$ abbreviates that hunks $\mathrm{x}$ and $\mathrm{y}$ are quasi-identical in the sense of overlapping in at least $98 \%$. The arrows refer to the accessibility relation among worlds.

This scenario would show a tension between (1) and (4) because, while being constructed under the assumption of (1), worlds $w_{3}$ and $w_{4}$ appear to falsify (4). In the first instance, they appear to falsify (V"), endorsement of which is Salmon's way of endorsing (4). The reason is as follows: originating from $m_{2}+C$ is possible for both $a$ and $b$, but the scenario reveals this property (namely, $\mathrm{S}_{2}$ ) to be sufficient for the existence of none, as $b$ does not exist in $\mathrm{w}_{3}$ and $a$ does not exist in $\mathrm{w}_{4}$. Contrary to ( $\mathrm{V}^{\prime \prime}$ ), therefore, properties like $S_{2}$ would not be sufficiency properties. Further reflection reveals also that there is no way of finding alternative properties with which to attempt to rescue (4). For nothing prevents $w_{3}$ and $w_{4}$ from being qualitatively indistinguishable, and even indistinguishable with respect to "the very matter they contain [...], differing only gratuitously over the fact of which [ship/table] is constituted by a certain hunk of matter" (Salmon 1982, 232). Consequently, packing into the C-constraints additional, or different, parameters will not help us eventually get a sufficiency property. The scenario appears to commit us to a pair of possible worlds which instantiate a mere haecceitistic switch, the existence of which Salmon finds paradoxical precisely because of the intuitiveness of (4). (It in fact commits us to something stronger than a haecceitistic switch: not only do the beings of $a$ and $b$ not supervene on qualitative character-in itself sufficient for the possibility of haecceitistic switches-but also they do not supervene on qualitative character plus identity of matter.)

Salmon's Solution. Salmon believes, however, that the tension between (1) and (4) is only apparent and that it can be resolved by denying instead that the accessibility relation among worlds is transitive; that is, by denying our thesis (2). He motivates this by assuming that adding $\mathrm{w}_{5}$ is a natural extension of the original scenario:

\begin{tabular}{|lllcr|}
\hline $\mathrm{w}_{1}:$ & $\mathrm{a} / \mathrm{m}_{0} / \mathrm{C}$ & $\Rightarrow \mathrm{w}_{2}:$ & $\mathrm{b} / \mathrm{m}_{3} / \mathrm{C}$ & \\
$\Downarrow$ & & & $\Downarrow$ & \\
$\mathrm{w}_{3}:$ & $\mathrm{a} / \mathrm{m}_{2} / \mathrm{C}$ & $\mathrm{w}_{4}:$ & $\mathrm{b} / \mathrm{m}_{2} / \mathrm{C}$ & $\left(\mathrm{m}_{0} \approx \mathrm{m}_{3}\right)$ \\
$\Downarrow$ & & & & \\
$\mathrm{w}_{5}:$ & $\mathrm{a} / \mathrm{m}_{3} / \mathrm{C}$ & & & \\
\end{tabular}

figure 2 
The actual world is $w_{1}$. In $w_{3}, a$ is constructed from $m_{2}$. From the fact that $m_{2} \approx m_{3}$, it follows-or so assumes Salmon-that, from $\mathrm{w}_{3}$, a could originate from $\mathrm{m}_{3}$. This assumption guarantees the existence of $\mathrm{w}_{5}$. By $\neg\left(\mathrm{m}_{0} \approx \mathrm{m}_{3}\right)$, $a$ cannot, from the point of view of the actual world $w_{1}$, originate from $m_{3}$. Consequently, $w_{5}$ is not possible relative to $\mathrm{w}_{1}$. This is a non-paradoxical argument for the failure of transitivity-i.e., for $\neg(2)$.

The denial of (2) would appear to solve the tension between (1) and (4). The paradoxical scenario was committed to the following accessibility facts among worlds: on the one hand, $\mathrm{w}_{1} \Rightarrow \mathrm{w}_{3}$ and, on the other, $\mathrm{w}_{1} \Rightarrow \mathrm{w}_{2}$ and $\mathrm{w}_{2} \Rightarrow \mathrm{w}_{4}$. Since transitivity does not hold, the latter two facts do not commit us to $\mathrm{w}_{1} \Rightarrow \mathrm{w}_{4}$. Principle (V") would be falsified only if $\mathrm{w}_{1} \Rightarrow \mathrm{w}_{3}$ and $\mathrm{w}_{1} \Rightarrow \mathrm{w}_{4}$, since only then would both $\mathrm{w}_{3}$ and $\mathrm{w}_{4}$ be accessible from $w_{1}$, thereby being, from $w_{1}$, both under the scope of the modal operators in ( $\left.V^{\prime \prime}\right)$. Let me elaborate. From $\mathrm{w}_{1}, a$ can originate from $\mathrm{m}_{2}$, and it does so in possible world $\mathrm{w}_{3}$ (which is accessible from $\mathrm{w}_{1}$ ). If, in $\mathrm{w}_{1}$, we apply ( $\mathrm{V}^{\prime \prime}$ ) to $a^{\prime}$ 's possibility of originating from $\mathrm{m}_{2}$, we get that in every possible world from $\mathrm{w}_{1}$-that is, in every world accessible from $\mathrm{w}_{1}$-in which some table originates from $\mathrm{m}_{2}$ (plus $\mathrm{C}$ ), that table is $a$. But isn't $\mathrm{w}_{4}$ a world that falsifies just this? Salmon answers this question in the negative, since we are now not committed to saying that $\mathrm{w}_{4}$ is possible (i.e., accessible) from $\mathrm{w}_{1}$. In other words, originating from $\mathrm{m}_{2}$ is not, from $\mathrm{w}_{1}$, a possibility for $b$. Therefore, from $\mathrm{w}_{1}$, ( $\left.\mathrm{V}^{\prime \prime}\right)$ does not imply that $b$ would be the outcome of making $\mathrm{m}_{2}$ into a table. Far from concluding that (V")-or (4)-is challenged by the paradoxical scenario, Salmon concludes instead that

on the contrary, such principles might be taken as showing that $w_{4}$ cannot be possible relative to $w_{1}$. (Salmon 1982, p. 240)

This manoeuvre allows Salmon to save, at least, the letter of ( $\left.V^{\prime \prime}\right)$.

Salmon's Assumption. But, as anticipated, the solution assumes that $\mathrm{w}_{5}$ is a natural addition and that it comes without hidden costs. I believe, however, that this assumption jeopardizes Salmon's attempt to save (4). It amounts, as we shall see first, to the contingency of (the essentiality of) essential properties and, consequently, to the contingency of sufficiency principles and individual essences. We shall see after this that this amounts to the failure of (4).

According to Salmon's non-transitivity scenario, from $\mathrm{w}_{1}$ it is not possible that $a$ originates from $\mathrm{m}_{3}$, but it is nonetheless possibly possible: if $a$ had been constructed from $\mathrm{m}_{2}$ (as it does in possible world $\mathrm{w}_{3}$ ), it would have been possible for it to originate from $\mathrm{m}_{3}$. But why is this so? Assume that, in $\mathrm{w}_{1}$, a essentially has the flexible property $\mathscr{F}_{0}$. Consequently, a instantiates $\mathscr{F}_{0}$ in all possible worlds where $a$ exists, like $\mathrm{w}_{3}$ (where $a$ originates from $\mathrm{m}_{2}$ ). So, in $\mathrm{w}_{1}, a$ has $\mathscr{F}_{0}$ and it has it essentially. In $\mathrm{w}_{3}, a$ has $\mathscr{F}_{0}$ too. Does it have it essentially there too? Salmon assumes that the answer is 'no'. For, by assuming the existence of $\mathrm{w}_{5}$, he assumes that, from the point of view of $\mathrm{w}_{3}, a$ can originate from $\mathrm{m}_{3}$, and this assumption is incompatible with $a$ having $\mathscr{F}_{0}$ essentially in $\mathrm{w}_{3}$ - for $\mathrm{m}_{3}$ is not quasi-identical with $\mathrm{m}_{0}$. Salmon assumes that, in $\mathrm{w}_{3}$, where $a$ comes from $\mathrm{m}_{2}$, $a$ 's essential property is $\mathscr{T}_{2}$ :

$\mathscr{T}_{2}=$ being originally made from $\mathrm{m}_{0}, \mathrm{~m}_{1}, \mathrm{~m}_{2}, \mathrm{~m}_{3}$, or $\mathrm{m}_{4}$ In $\mathrm{w}_{3}$, therefore, $a$ instantiates both $\mathscr{F}_{0}$ and $\mathscr{F}_{2}$ (among others). So far so good: they are disjunctive properties that share some of their disjuncts. And while the former was $a^{\prime}$ s essential property in $\mathrm{w}_{1}$, in $\mathrm{w}_{3}$ it is the latter instead. So which properties are essential to 
to $a$ is, across worlds, an inconstant matter for Salmon. Such contingency is not mandatory, though. In $\mathrm{w}_{1} a$ has a range of possible origins: $\left\{\mathrm{m}_{-2}, \mathrm{~m}_{-1}, \mathbf{m}_{\mathbf{0}}, \mathrm{m}_{1}, \mathrm{~m}_{2}\right\}$. In $\mathrm{w}_{3}, a$ realizes one of them: $\mathrm{m}_{2}$. This realization is compatible with $a$ retaining the same range of possible origins in $w_{3}$. Salmon, however, assumes that it has changed, the new range being $\left\{\mathrm{m}_{0}, \mathrm{~m}_{1}, \mathbf{m}_{2}, \mathrm{~m}_{3}, \mathrm{~m}_{4}\right\}$, where the realized possibility appears at the centre of the new range. In general terms, and more precisely, the assumption is this:

Salmon's Assumption: For any world, w, and for any artefact $a$ in $\mathrm{w}, a$ 's realized possibility in $\mathrm{w}$ is at the centre of $a$ 's range of possibilities from $\mathrm{w} .{ }^{8}$

This assumption is, no doubt, related to the intuition behind flexible-(EMOA) but it goes beyond it. Intuitively, an artefact's essential properties are to some extent flexible regarding the material origins of that artefact, and this is neutral on whether these flexible essential properties are in turn necessarily essential to the artefact, or only contingently essential.

As a straightforward consequence of the contingency of (the essentiality of these flexible essential properties, the range of sufficiency properties for an artefact also changes from world to world and, with it, its individual essence too. As illustrated above, the inflexible properties $S_{-2}$ to $S_{2}$ are, from $w_{1}$, sufficient for $a$ 's existence, and the flexible $\mathcal{S}_{0}$ is its individual essence. On the basis of what has emerged here, it is immediate to see that, from the point of view of $\mathrm{w}_{3}$, the sufficiency properties are instead $\mathrm{S}_{0}$ to $\mathrm{S}_{4}$, and its individual essence, $\mathcal{S}_{2}$. As we shall next unfold, this jeopardizes Salmon's attempt to resolve the tension between (1) and (4).

The failure of (4). The contingency of essences-more rigorously: the contingency of which properties are individual essences of which entities-trivially requires their relativization to worlds: as just seen, $\mathcal{S}_{0}$ is the individual essence of $a$ in $\mathrm{w}_{1}$, but not in $\mathrm{w}_{3}$ (where $\mathcal{S}_{2}$ is instead). But there is a further parameter to which we should relativize essences on Salmon's ontological picture; namely, entities. This can be illustrated by playing to add worlds into figure 1 according to Salmon's modal commitments.

Salmon has already shown us two key moves of the game. First, $\mathrm{w}_{2}$ was placed into the original scenario because, although from $\mathrm{w}_{1}$ a cannot be made from $\mathrm{m}_{3}$, some table can, and $\mathrm{w}_{2}$ and possibile $b$ play the role of accounting for that possibility. Second, as seen above and illustrated with figure 2 , he then added $w_{5}$ to the original scenario on the basis that, according to his rules (in particular, according to Salmon's Assumption), a can, from $\mathrm{w}_{3}$, be made from $\mathrm{m}_{3}$, and $\mathrm{w}_{5}$ plays the role of accounting for this possibility for $a$. These two moves can be iterated. The first one shows us how to expand figure 1 horizontally, and the second one, vertically. By iterating these moves, we end up with an (indefinitely expansible) ontological picture looking like this:

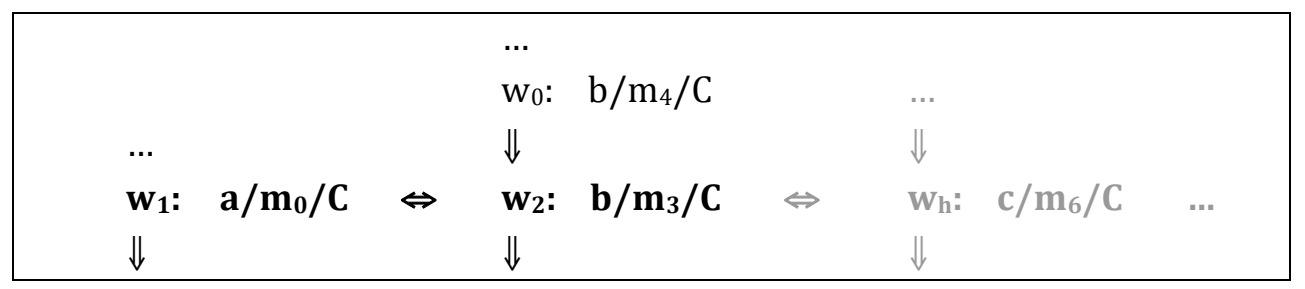

${ }^{8}$ I antecedently identified this assumption in (Roca-Royes, 2006). 


\begin{tabular}{|lllllll|}
\hline $\mathrm{w}_{3}:$ & $\mathrm{a} / \mathrm{m}_{2} / \mathrm{C}$ & $\mathrm{w}_{4}:$ & $\mathrm{b} / \mathrm{m}_{2} / \mathrm{C}$ & $\mathrm{w}_{\mathrm{i}}:$ & $\mathrm{c} / \mathrm{m}_{5} / \mathrm{C}$ & $\ldots$ \\
$\Downarrow$ & & $\Downarrow$ & & $\Downarrow$ & & \\
$\mathrm{w}_{5}:$ & $\mathrm{a} / \mathrm{m}_{3} / \mathrm{C}$ & $\mathrm{w}_{6}:$ & $\mathrm{b} / \mathrm{m}_{1} / \mathrm{C}$ & $\mathrm{w}_{\mathrm{j}}:$ & $\mathrm{c} / \mathrm{m}_{4} / \mathrm{C}$ & $\ldots$ \\
$\Downarrow$ & & $\Downarrow$ & & $\Downarrow$ & & \\
$\mathrm{w}_{7}:$ & $\mathrm{a} / \mathrm{m}_{4} / \mathrm{C}$ & $\mathrm{w}_{8}:$ & $\mathrm{b} / \mathrm{m}_{0} / \mathrm{C}$ & $\mathrm{w}_{\mathrm{k}}:$ & $\mathrm{c} / \mathrm{m}_{3} / \mathrm{C}$ & $\ldots$ \\
$\ldots$ & & $\ldots$ & & $\ldots$ & & $\ldots$ \\
\hline
\end{tabular}

figure 3

Reflection on figure 3 reveals that, for each $\mathcal{S}$-type flexible property, $\mathcal{S}_{\mathrm{i}}$, there are distinct worlds $\left(w, w^{\prime}\right)$ and distinct entities $\left(e, e^{\prime}\right)$ such that:

(a) $\int_{\mathrm{i}}$ individuates $e$ in $w$

(b) $\quad \int_{\mathrm{i}}$ individuates $e^{\prime}$ in $w^{\prime}$

The following are instances of that general claim:

(a') $\quad \int_{3}$ individuates $a$ in $w_{5}$

(b') $\quad \int_{3}$ individuates $b$ in $w_{2}$

(a") $\quad \int_{2}$ individuates $a$ in $w_{3}$

(b") $\quad \int_{2}$ individuates $b$ in $w_{4}$

From this, the relativity of essences not only to worlds but also to entities follows: not only it is contingent which individual essence $a$ has in which world, but also it is contingent which entity $\mathcal{S}_{3}$ (for instance) is an individual essence of. ${ }^{9}$ If we consider the total space of brute worlds, ${ }^{10} \mathcal{S}$-type properties are, at best, uniqueness properties. They are not, however, individuative properties in the absolute (brute) sense. This will emerge as the ultimate source of the problem.

A preliminary excursus is convenient, first, to give credit to a related objection by Lewis and, second, to distinguish it from the objection to follow. Lewis (1986) objected that the world-relativity of essences turns Salmon's account into an anti-essentialist one: if it is possible for an object, $a$, to have different essential properties from its actual ones, this shows that those properties are not essential-to- $a$.

There is worse to come: couldn't we trace a very long chain of very small revisions leading from you to a poached egg? (Lewis 1986, p. 244)

This objection exploits only the world-relativity of essences. Just one-sufficiently long-(vertical) chain of worlds from figure 3 is enough to ground this worry. ${ }^{11}$

I will present a different (related) objection that exploits the world+entity-relativity of essences; the kind of relativity needed to secure pairs of (brute) worlds-like $\mathrm{w}_{3}$ and

\footnotetext{
${ }^{9}$ This does not follow from the mere contingency of essences. The chain on the left already implies the contingency of essences (of $a$ in particular) but not yet its relativization to entities. For the latter, we need a further chain, like the middle one. Salmon is committed to this chain from the moment he wants to account for this possibility: "it is possible (from $\mathrm{w}_{1}$ ) to make some table from $\mathrm{m}_{3}$."

10 The notion of brute world is to be understood thus: $\mathrm{w}$ is a brute world iff for some $\mathrm{n} \geq 0$, either $\mathrm{w}$ is a possiblyn possible world or the actual world is a possibly ${ }^{\mathrm{n}}$ possible world from $\mathrm{w}$.

${ }^{11}$ Salmon (1989) addresses this objection by stressing the difference between "ways things might be" (implying possibility) and "ways for things to be" (implying neither possibility nor possibility ${ }^{n}$ possibility, although compatible with both). I will not enter the details of that discussion here, but one can find them in Salmon (1982 and 1989) and Lewis (1986).
} 
$\mathrm{w}_{4}$-instantiating what looks like a haecceitistic switch. As we have seen, Salmon learns to live with $\mathrm{w}_{3}$ and $\mathrm{w}_{4}$ by denying that they are both possible: $\mathrm{w}_{3}$ is possible, but $\mathrm{w}_{4}$ is only possibly possible. Lewis (1986) complains about this too:

It is not so, if we ignore worlds inaccessible from ours, that we have a case of haecceitistic difference. [...] In these questions of haecceitism and essence, by what right do we ignore worlds that are deemed inaccessible? (Lewis 1986, p. 246)

I shall turn this second complaint into an objection by showing that Salmon's distinction between the possible and the possibly possible does not help. It can be sloganized by paraphrasing Lewis's first objection: if it is possible for $b$ to have $a$ 's essential properties, this shows that those properties are not essential-to-a. Let us unfold it.

I agreed above that Salmon's solution validates the letter of (V"). I will now argue that it violates its spirit, for it violates its underlying anti-haecceitist intuition that being supervenes on qualitative character plus identity of matter (and of C-constraints). ${ }^{12}$ This is the diagnosis of where things have gone wrong: Salmon (1982) starts with the antihaecceitist intuition that implies the existence of sufficient conditions for artefacts. The correctness of this intuition should preclude the existence of haecceitistically different worlds. Some pages before announcing his $\neg(2)$ solution, Salmon encodes this intuition, in ( $\left.V^{\prime \prime}\right)$, in a way that will be accepted by those whose modal thinking validates (2)-that is, whose modal thinking validates the characteristic axiom of modal logic S4. Salmon ends up, however, with a non-S4 logic. In his system, (V") becomes weaker than its underlying intuition because, since we cannot assume transitivity, the modal operators in (V") range over many fewer worlds than those for which the anti-haecceitist intuition holds. This difference in strength is the reason why his account allows for worlds, such as $\mathrm{w}_{3}$ and $\mathrm{w}_{4}$, that, while not falsifying ( $\left.\mathrm{V}^{\prime \prime}\right)$, still generate the same puzzlement and raise the same questions by means of which Salmon motivated the anti-haecceitist intuition: why is $a$ in world $\mathrm{w}_{3}$ not numerically identical to $b$ in $\mathrm{w}_{4}$, given that those worlds are atom-per-atom identical? As these remarks reveal, when the letter of ( $V^{\prime \prime}$ ) and its underlying anti-haecceitist intuition come apart, it is no merit to show that the account validates the former; one should show that the account validates the intuition, or else a principle that, under the assumption of $\neg S 4$, appropriately encodes it. ${ }^{13}$

On the basis of this diagnosis, there are two reactions that come in the form of fair complaints against Salmon's views. First, one can ask that ( $\left.\mathrm{V}^{\prime \prime}\right)$ be strengthened so as to match, in a $\neg$ S4-framework, the strength of the anti-haecceitist intuition it is supposed to encode. The following is a good way of accordingly revising ( $\left.\mathrm{V}^{\prime \prime}\right)$ :

( $\left.V^{\prime \prime \prime}\right) \quad$ If it is possiblyn possible $(n \geq 0)$ for a table $x$ to be the only table [in a world] originally constructed (by a certain artisan in a certain place at a certain time)

\footnotetext{
12 Strictly speaking, this is weaker than the anti-haecceitist intuition (according to which being supervenes on qualitative matter). This partially explains why Salmon is so reluctant to deny (V"), since denying it would result in something stronger than haecceitism: not only being would not supervene on qualitative character but also it would not supervene on qualitative character plus identity of matter and other C-constraints. I have been speaking loosely of the (V')-intuition as an anti-haecceitist one.

${ }^{13}$ Note that, when working with modal logic S4-thereby endorsing our thesis (2) - principle (V") exactly encodes the anti-haecceitist intuition because, when transitivity holds, we cannot interestingly play with the scope of the modal operators occurring in (V") in the way that Salmon played with it to try to solve the tension between (1) and (4).
} 
from a certain hunk of matter $y$ according to plan $P$, then necessarilyn necessary $(n \geq 0)$, any table that is the only table [in a world] to be originally constructed (by the very same artisan in the very same place at the very same time) from the very same hunk of matter $y$ according to the very same plan $P$ is the very same table $x$ and no other. ${ }^{14}$

But Salmon's account does not validate ( $\left.\mathrm{V}^{\prime \prime \prime}\right)$ : both $\mathrm{w}_{3}$ and $\mathrm{w}_{4}$ are under the scope of its modal operators, and they falsify it. Consequently, Salmon hasn't managed to dissolve the tension between (1) and (4). In particular, Salmon's solution does not accommodate (4) - the claim that there are sufficient conditions for the existence of artefacts.

The second reaction-leaving for now aside the conclusion just reached-is to ask for an answer to Salmon's very own anti-haecceitist motivating question: "What more [beyond qualitative character and identity of matter and C-constraints] is there to being this very table [a]?" (Salmon 1982, 211). If that could be satisfactorily answered, there could still be room to accommodate (4). I shall argue, however, that Salmon's ontological picture cannot engender a satisfactory answer. The argument will have two key steps: (i) that any potentially satisfactory answer will need to appeal to accessibility facts; and (ii) that no answer that appeals to accessibility facts will (in Salmon's ontological picture) be satisfactory. Let me start with (i). Considered as brute worlds, the only difference between $\mathrm{w}_{3}$ and $\mathrm{w}_{4}$ is the phenomenon to be explained; namely, the haecceitistic switch between $a$ and $b$. There is no way of explaining this difference if we just focus on those worlds' intrinsic features. This was exactly the source of The Four Worlds Paradox. Yet, when transitivity does not hold, there are also relational differences between these two worlds like, for instance, the fact that $\mathrm{w}_{3}$ is accessed from $\mathrm{w}_{1}$ (where $a$ exists) but not from $\mathrm{w}_{2}$ (where $b$ instead exists); whereas it is the other way around in the case of $\mathrm{w}_{4}$. These relational facts will need to be involved in any potential answer because they are the only ones that make a difference with the paradoxical scenario. As anticipated in (ii), however, appeal to these relational (i.e., accessibility) facts cannot engender a satisfactory explanation. Let us see why. What the existence of $\mathrm{w}_{3}$ and $\mathrm{w}_{4}$ shows is that instantiation of the (inflexible) property $\mathrm{S}_{2}$-namely, being originally made from $m_{2}$, by $A$, according to $P$, and at $t$ and $p$-is a (brute) sufficient condition neither for $a$ 's existence nor for $b$ 's. Therefore, the mere fact that it is instantiated cannot explain why it is $a$ (and not $b$ ) that exists in $\mathrm{w}_{3}$. In other words, instantiation of this fact is insufficient for the being of a to supervene upon it; for that fact exists also in $\mathrm{w}_{4}$, where $a$ does not exist. As suggested, to obtain an absolute sufficient condition, Salmon should constrain further that property by means of accessibility facts, thereby obtaining something along the following lines: being made from $m_{2}$ (plus $C$ ) in a world accessed by another world in which a [b in the other case] has been constructed by a hunk of matter overlapping to a high degree with $m_{1}$. This, however, would only open an explanatory regress, since we would now need to explain what makes it the case that the world mentioned in this further constraint is an $a$-world rather than a $b$-world. If we look again at figure 3 above, the ultimate explanation

\footnotetext{
14 This principle is weaker than it should, since the worlds captured by it belong to a proper sub-model of the total modal space; namely: the generated sub-model that has the actual world as its bottom element. Strictly, the principle should capture also the worlds for which the actual world is a possiblyn possible world $(n \geq 0)$. For current purposes, however, the formulation in (V'") suffices.
} 
Salmon owes us is an explanation of why the left (vertical) chain of worlds is an $a$-chain rather than a $b$-chain. For all the argument requires, the differences between two such chains are only haecceitistic and, given this, it is hard to imagine what a satisfactory answer could consist of. Rather, we are facing the original paradox on a bigger scale: this time, at the level of haecceitistically different chains of worlds. At such level, furthermore, Salmon has lost the possibility of appealing to (further) relational properties: the chains do not relationally differ.

Someone might object that this second reaction is unfair on the following grounds. In the quotation above by means of which Salmon motivates the anti-haecceitist intuition and his principle ( $\left.\mathrm{V}^{\prime \prime}\right)$, he speaks of possible worlds, as opposed to of brute worlds as I have been doing. To recall, he asks us there to consider "two tables in two different possible worlds [that] are constructed from the very same stuff". As a result-the complaint would go-he does not need to provide the answers I am demanding here, simply because there are no two such tables in possible worlds. In response: this is no defence on behalf of Salmon. His motivation of (V") is prior to both the formulation and the treatment of the paradox, and should be taken as neutral on issues about the logical properties of the accessibility relation. If we read 'possible worlds' in the above quotation, and other analogously motivating paragraphs of (Salmon 1982), in this neutral way-i.e., meaning brute worlds-Salmon's solution is committed to the claim that two such tables can "fail to be the very same table". Him being an anti-haecceitist, one can legitimately ask him what makes them different tables. After having endorsed non-transitivity, he should have gone back to those (motivating) questions and answered them. What turns this complaint into an objection is that, as seen, no satisfactory answer is forthcoming.

To recap: Salmon's solution to the paradox saves the letter of ( $\left.V^{\prime \prime}\right)$ but not its spirit. The considerations above can be seen as an articulation of Lewis' explicit, though admittedly too brief, remark that Salmon's non-transitivity strategy "gives away the point of anti-haecceitism in order to defend the words 'Adam could not have occupied the Noah role'” (Lewis 1986, p. 247).

Salmon's denial of (5) and reliance on (3). So far, we have seen that, after endorsing (1), Salmon chooses to deny (2) and does not manage to accommodate (4). We shall finish the scrutiny of his view by seeing, first, that he is also committed to denying (5) and, second, that he implicitly relies on (3). Let us re-state those two theses:

(3) There are no coincident artefacts of the same kind, fully sharing their spatiotemporal region

(5) If $P$ is the individual essence of an artefact, then all properties analogous to $P$ are individual essences of artefacts too

I shall start with the denial of (5). In Salmon's scenario, $b$ originates, in $\mathrm{w}_{2}$, from $\mathrm{m}_{3}$. Given Salmon's assumption, the flexible property $\mathcal{S}_{3}$-being originally constructed from any of $m_{1}, m_{2}, m_{3}, m_{4}$ or $m_{5}$ plus $C$-is an individual essence of $b$ in $w_{2}$. But given that Salmon assumes the contingency of essences, this leaves open which property individuates $b$ in the actual world $\mathrm{w}_{1} \cdot{ }^{15}$ Open, but only to some extent. For it must be a

\footnotetext{
15 Regardless of whether $b$ exists in $\mathrm{w}_{1}$, we can legitimately ask which property individuates $b$ in $\mathrm{w}_{1}$. For, in $w_{2}, b$ comes from $m_{3} . w_{2}$ is accessed by $w_{1}$, which means that $w_{2}$ realizes one of $w_{1}$ 's
} 
property compatible with the fact that $\mathrm{w}_{2}$ (where $b$ originates from $\mathrm{m}_{3}$ ) is accessed by $\mathrm{w}_{1}$. The property must therefore involve $\mathrm{m}_{3}$ as one of the possible origins. $\int_{2}$ could, prima facie, be such property:

$\mathcal{S}_{2}=$ being originally constructed from $\mathrm{m}_{0}, \mathrm{~m}_{1}, \mathrm{~m}_{2}, \mathrm{~m}_{3}$, or $\mathrm{m}_{4}$ (plus $\mathrm{C}$ )

However, in $\mathrm{w}_{1}$, where $a$ originates from $\mathrm{m}_{0}, \mathcal{S}_{0}$ individuates a (again by Salmon's assumption). $\mathcal{S}_{0}$ and $\mathcal{S}_{2}$ share several disjuncts, for instance the one involving $\mathrm{m}_{2}$. As a result, Salmon cannot let $\int_{2}$ individuate $b$ in $\mathrm{w}_{1}$ because, if it did, $\mathrm{m}_{2}$ would be, from $\mathrm{w}_{1}$, a possible origin for both $a$ and $b$, and this would jeopardize even the letter of ( $\mathrm{V}^{\prime \prime}$ ). For this would give us two possible worlds where a table is made from $\mathrm{m}_{2}$ : in one of them, only $a$ would exist and, in the other, only $b$ would. As a result, being originated from $m_{2}$ would be, contra ( $\mathrm{V}^{\prime \prime}$ ), sufficient for the existence of neither $a$ nor $b$.

By continuing to search for a property that avoids this problem, we arrive at the general claim that, whichever is the individual essence $b$ has in $\mathrm{w}_{1}$, it must not involve, as one of its satisfaction conditions, any origin that is already in the range of possibilities for any other actual (or possible) entity from w1. For all we know about Salmon's scenario, one such property could be $\mathcal{S}_{5}$ :

$\mathcal{S}_{5}=$ being originally constructed from $\mathrm{m}_{3}, \mathrm{~m}_{4}, \mathrm{~m}_{5}, \mathrm{~m}_{6}$ or $\mathrm{m}_{7}$ (plus C)

Generalizing, suppose we could name all pieces of matter analogous to $\mathrm{m}_{0}$ and linearly order them by similarity. ${ }^{16}$ Given that there is, in $\mathrm{w}_{1}$, a table, $a$, made from $\mathrm{m}_{0}$, whose possible origins are $\left\{\mathrm{m}_{-2}, \mathrm{~m}_{-1}, \mathbf{m}_{\mathbf{0}}, \mathrm{m}_{1}, \mathrm{~m}_{2}\right\}$, this-plus Salmon's endorsement of (V")constraints which properties are allowed, in Salmon's framework, to individuate other tables from the point of view of $\mathrm{w}_{1}$. Only the following partition is accepted from $\mathrm{w}_{1}$ :

$$
\begin{array}{ccc}
\left.\ldots, \mathrm{m}_{-9}, \mathrm{~m}_{-8}\right\} & \left\{\mathrm{m}_{-7}, \mathrm{~m}_{-6}, \mathbf{m}_{-5}, \mathrm{~m}_{-4}, \mathrm{~m}_{-3}\right\}, \\
\mathcal{S}_{-10} & \left.\mathrm{~S}_{-2}, \mathrm{~m}_{-1}, \mathbf{m}_{0}, \mathrm{~m}_{1}, \mathrm{~m}_{2}\right\}, & \left\{\mathrm{m}_{3}, \mathrm{~m}_{4}, \mathbf{m}_{5}, \mathrm{~m}_{6} \ldots\right. \\
\mathcal{S}_{0}(\text { for } a) & \mathcal{S}_{5}(\text { for } b)
\end{array}
$$

This is the denial of (5). Property $\mathcal{S}_{2}$ is analogous to $\mathcal{S}_{0}$ but the former, unlike the latter, does not individuate, from the point of view of the actual world $\left(\mathrm{w}_{1}\right)$, any possibile. This can be taken as an extra cost of the account. ${ }^{17}$

What about (3)? My argument above to the effect that "Salmon cannot let $\mathcal{S}_{2}$ individuate $b$ " implicitly assumed that the denial of (3) is not available. For according to that

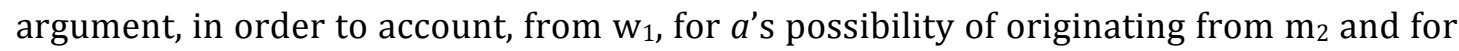
$b$ 's possibility of originating also from $\mathrm{m}_{2}$, we would need two possible worlds; one where only $a$ exists and one where only $b$ exists. I simply ignored there the theoretical possibility of letting one single world account for both possibilities, and claiming $a$ and $b$ be, in that single world, fully coincident entities. So Salmon is committed to denying (5) to the extent he relies on (3). And he does rely on (3). The paradoxical character of

possibilities in relation to $b$. So, $w_{1}$ encodes what possibilities there are for $b$ from $w_{1}$. Which part of $w_{1}$ is responsible for this? The most natural answer is: 'the essence that $b$ has in $w_{1}$, whether $b$ is actual there, or merely a possibile'.

16 This is, once more, harmless simplification.

${ }^{17}$ Thesis (5) hasn't been much discussed in the literature and, yet, it is implicitly endorsed more often than is noticed. Peacocke (2002), for instance, endorses it to extend individuation principles of actual individuals to mere possibilia. More generally, something very close to (5) helps making a case for the possible existence of non-actual individuals. 
figure 1 consists precisely in the existence of two worlds $-\mathrm{w}_{3}$ and $\mathrm{w}_{4}$-that instantiate a haecceitistic switch. At no point did Salmon consider blocking the paradox by endorsing fully (spatio-temporally) coincident entities. This will be Williamson's solution.

To wrap up the whole of $\S 2$ : Salmon's solution only manages to accommodate, at best, two of the five original theses: (1) and (3). Because each of (1)-(5) is better supported-theoretically or intuitively-than its salient rival, this is an expensive solution to the paradox. We shall next move on to scrutinize Williamson's solution. As anticipated in $\S 1$, it promises to be cheaper in that it denies only (3). ${ }^{18}$

\section{Scrutinizing Williamson's view.}

In his Identity and Discrimination (1990), Williamson constructs, also on the basis of (1), a different paradox which we can call 'the (Many) Two Earrings Paradox'. He solves it, ultimately, by denying (3). I shall scrutinize Williamson's view, not by presenting and dealing with his paradox, but by applying his solution to Salmon's paradox. ${ }^{19}$ The emphasis will be on how Williamson's approach compares to Salmon's. We shall see how, once (1) is endorsed, denying (3) allows us to accommodate the rest of our five theses: (4), (2) and (5).

One of the effects of denying (3) is the merging of $\mathrm{w}_{3}$ and $\mathrm{w}_{4}$ while not identifying $a$ and $b: a$ and $b$ become distinct entities which fully share the spatio-temporal region they occupy. Salmon's four-world scenario turns thus into a three-world one:

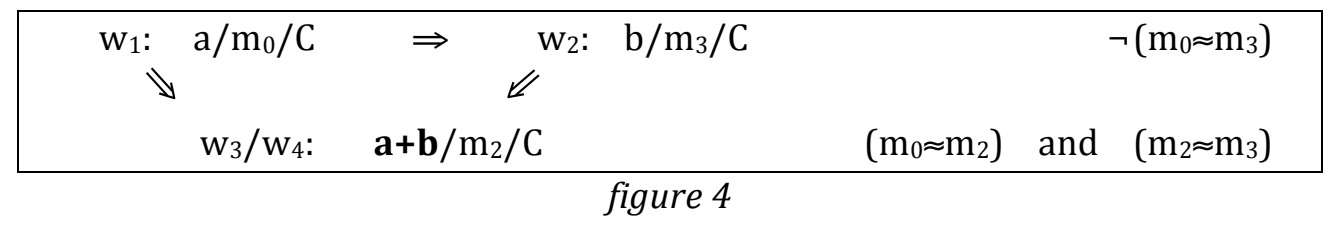

Tables $a$ and $b$ are distinct because, while they might coincide in some worlds where they share all their categorical properties, they do not always coincide (like in $\mathrm{w}_{1}$ or $\mathrm{w}_{2}$ ). And they do not always coincide because they differ in modal/essential properties. We shall take it here that, in the current Williamsonian account, $\mathcal{S}_{0}$ individuates $a$ and that $\mathcal{S}_{3}$ individuates $b$. (This explains why $a$ does not exist in $\mathrm{w}_{2}$ and $b$ does not exist in $\mathrm{w}_{1}: \mathrm{m}_{3}$ is not a piece of matter $a$ could come from and $\mathrm{m}_{0}$ is not a piece of matter $b$ could come from.) Let us now see how the other theses can be accommodated.

The case of (5): We saw at the very end of $\S 2$ that, in a framework that endorses (1), denying (3) renders a way of accommodating (5). Given that our game here is to accommodate as many theses as possible, we accommodate it. Consequently, for any $i$,

\footnotetext{
${ }^{18}$ We have now stock to make explicit the mutual inconsistency of (1)-(5): If (5) is true, and if the individual essences are flexible as a consequence of the truth of (1), there are pairs of individual essences, e.g., $S_{n}$ and $\int_{n+2}$, that overlap in satisfaction conditions, e.g., $S_{n+1}$. If (4) is also true, these satisfaction conditions are sufficient for the existence of more than one entity of the same type; e.g., $a$ and $b$. This implies the negation of (3).

19 I will radicalize Williamson's solution. Williamson (1990) doesn't deny (3) for (his) tables. He denies it for ontologically more fine-grained entities, which we might call 'tables*', determinately individuated by specific ranges of origins. For reasons I cannot extend on here, Williamson's tables (determinately) satisfy that 'they are individuated by ranges of origin', but (for reasons orthogonal to vagueness) there is no range of origins such that, determinately, individuates this (a particular) table. That is so (vagueness aside), however, for Salmon's tables. Therefore, this "radicalization" is necessary because what would be Williamson's tables* are Salmon's tables.
} 
the (flexible) property $\int_{\mathrm{i}}$ will be, in this framework, an individual essence. Whereas Salmon could admit (from the actual world $\mathrm{w}_{1}$ ) only one partition, according to which only $\mathcal{S}_{-10}, \mathcal{S}_{-5}, \mathcal{S}_{0}, \mathcal{S}_{5}, \ldots$ are individual essences:

$$
\begin{array}{ccc}
\left.\ldots, \mathrm{m}_{-9}, \mathrm{~m}_{-8}\right\}, & \left\{\mathrm{m}_{-7}, \mathrm{~m}_{-6}, \mathbf{m}_{-5}, \mathrm{~m}_{-4}, \mathrm{~m}_{-3}\right\}, \\
\mathcal{S}_{-10} & \left\{\mathrm{~m}_{-2}, \mathrm{~m}_{-1}, \mathbf{m}_{0}, \mathrm{~m}_{1}, \mathrm{~m}_{2}\right\}, & \left\{\mathrm{m}_{3}, \mathrm{~m}_{4}, \mathbf{m}_{5}, \mathrm{~m}_{6} \ldots\right. \\
\mathcal{S}_{-5}(\text { for } a) & \mathcal{S}_{5}(\text { for } b)
\end{array}
$$

Williamson allows for any of them; where (graphically) new partitions result from transposing the parenthesis above, one, two, three or four places to the right or to the left. These partitions are called, in Williamson's technical approach, 'M-relations'. We don't need to get into technicalities here, but it is instructive to see Williamson's explicit disagreement with Salmon: "since any two of these are isomorphic, there is no reasonable way of choosing between them" (Williamson 1990,132). According to the Williamsonian treatment we are now exploring, therefore, any set of five correlative origins (plus the C-constraints) individuates a possible table. Unlike what we saw in the case of Salmon, therefore, $\mathcal{S}_{2}$, from the actual world $\mathrm{w}_{1}$, does individuate some possible entity; an entity that Salmon had to abort from his ontology.

The case of (2). Given the three-world scenario, we don't have two worlds instantiating a haecceitistic switch and, as a result, we are under no pressure to deny (2). So we accommodate it too. Importantly, accommodating (2) requires the negation of Salmon's Assumption for, as seen in $\S 2$, that assumption enables a valid argument against (2). Denying this assumption allows us to keep, again contra Salmon, the necessity of individual essences-more rigorously: the necessity of which property $\int_{i}$ is an individual essence of which entity - thereby avoiding any (Lewisian-style) charge of anti-essentialism.

The case of (4). By keeping the necessity of essences, we keep too the necessity of sufficiency properties, with which the current account can be said to respect both (4) the spirit of (V"). For the account has no difficulty in accommodating conditionals like the following (whose antecedents are true in the account): If the (inflexible) property $\mathrm{S}_{2}$-originating from $m_{2}$ plus $C$-is a sufficient condition for the existence of $a$, then, at absolutely any (brute) world in which something satisfies $S_{2}$, $a$ exists there and satisfies that property. Surely, $a$ will not be the only entity satisfying it: satisfaction of $S_{2}$ is also (absolutely) sufficient for the existence of other entities, like $b$, with which $a$ shares $\mathrm{m}_{2}$ as a possible material origin. Therefore, both $a$ and $b$ exist in any world in which something is made from $m_{2}(+C)$, since that is absolutely sufficient for the existence of each. Despite the fact that many beings supervene on the same qualitative-plus-matter facts, the anti-haecceitist intuition can be said to be satisfied in that, for any two (brute) worlds qualitatively-and-matter identical, the same many beings supervene in each of them. That is, there is no difference in numerical identities without a subvenient difference. To this extent, therefore, the spirit of ( $\left.V^{\prime \prime}\right)$ is accommodated. This time, however, it is its letter that is defective because, given the current account's denial of (3), the uniqueness condition in the antecedent of ( $\left.V^{\prime \prime}\right)$ will never be satisfied.20 On the current account, it is not origins but ranges of origins that (absolutely) individuate entities. Consequently, an unproblematic and accordingly revised cross-world identification principle could read as follows:

${ }^{20}$ This assumes that (3) is necessarily false. This is the intended view under exploration. 
$\left(\mathrm{V}^{*}\right) \quad$ If it is possible for table $\mathrm{x}$ to be the only table made (in C-conditions) from a hunk of matter which overlaps with $m_{0}$ to a high degree and such that $m_{0}$ is at the centre of x's possible origins, then, necessarily, any possible table that is the only table made (in C-conditions) from a hunk of matter that overlaps with $m_{0}$ to a high degree and such that $m_{0}$ is at the centre of its possible origins is table $a$ and no other.

To offer a graphic illustration of the current view's ontology, let me name some of the possibilia that Salmon's ontology aborted but the Williamsonian one does not: ' $c$ ' names the possibile individuated by $\mathcal{C}_{1}$; ' $\mathrm{d}$ ', the one individuated by $\mathcal{S}_{2}$; ' $e$ ', the one individuated by $\mathcal{S}_{4}$; and ' $\rho$ the one individuated by $\mathcal{S}_{5}$. The Williamsonian picture looks like this:

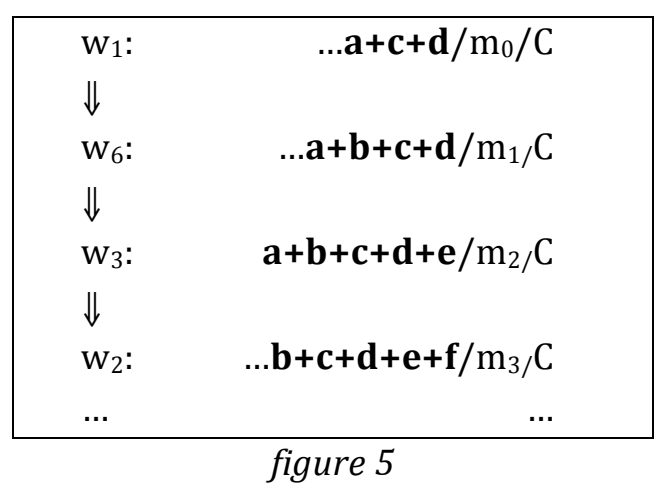

To explain it: I am ordering the worlds vertically by similarity of the pieces of matter. In every world, we keep $a$ 's essence the same $\left(\mathcal{S}_{0}\right)$, and this is why $a$ has disappeared in $\mathrm{w}_{2}$, and also why Salmon's $\mathrm{w}_{5}$ - where $a$ originated from $\mathrm{m}_{3}$ - does not exist in this picture. Also $b$ 's essence is the same in every world $\left(\int_{3}\right)$, and this is why it does not exist in $w_{1}$. For analogous reasons, $e$ (individuated by $\mathcal{S}_{4}$ ), doesn't exist in $\mathrm{w}_{1}$; etc.

This account is committed to more possible individuals than Salmon's. It would be too hasty, however, to conclude from here that Salmon's account is ontologically superior. For by keeping transitivity, we have here that $\mathrm{w}_{1} \Rightarrow \mathrm{w}_{2}$. This fact accounts, without the need of expanding the picture horizontally, for the intuitive possibility that, from $\mathrm{w}_{1}, \mathrm{~m}_{3}$ be made into some table. Therefore, whereas the current account does with a unique chain of worlds with multiply inhabited tables (with transitivity), Salmon's-which had to grow horizontally-needs a multiplicity of chains of worlds with uniquely inhabited tables (without transitivity). ${ }^{21}$ Only in Salmon's ontology we would find uncountably many pairs of worlds instantiating haecceitistic switches. It is therefore difficult to compare the accounts' ontological costs.

To conclude so far: of the two solutions considered, the Williamsonian one is preferable. However, it is committed to fully coincident entities of the same kind-it is committed to $\neg(3)$ - and this is a considerable price. The literature contains independent reasons to believe in closely related phenomena: the statue and the lump would fully spatially coincide at some times; and the many cats quasi spatio(-temporally) coincide with Tibbles. But whereas the statue and the lump are of different kind, and whereas the many cats do not fully spatially coincide, the Williamsonian coincidents are

\footnotetext{
21 To be precise, instead of 'inhabited tables' I should say 'inhabited table-shaped-structuredmatter'. I chose the former for the sake of easy-readability.
} 
of the same kind and fully coincident. For believing in this kind of coincidents, we do not seem to have independent reasons. ${ }^{22}$ This is a convenient dialectical point to explore the potential theoretical benefits of denying thesis (1) instead.

\section{An inflexible-(EMOA) solution}

Flexible-(EMOA) is intuitively more plausible than its inflexible rival. This has been granted since $\S 1$. The relevant question is whether denying the intuition which supports it can result in the best (reflectively) equilibrated view. I shall argue that it does. Because the Williamsonian solution has already been argued to be superior to Salmon's, I only need to compare the current inflexible-solution to Williamson's. In terms of numbers, there is a tie: each accommodates exactly four of our five theses. The tie can arguably be broken, however, by showing how ontologically simpler the inflexible(EMOA) account is and by arguing that, while both can be said to accommodate (4), the current proposal better accommodates the anti-haecceitist intuition behind it.

\section{Breaking the tie}

The ontology of the inflexible-(EMOA) proposal looks like this:

\begin{tabular}{|ll|}
\hline$\ldots$ & $\ldots$ \\
$\mathrm{w}_{1}:$ & $\mathbf{a} / \mathrm{m}_{0} / \mathrm{C}$ \\
$\Downarrow$ & \\
$\mathrm{w}_{3}:$ & $\mathbf{b} / \mathrm{m}_{1 /} \mathrm{C}$ \\
$\Downarrow$ & \\
$\mathrm{w}_{6}:$ & $\mathbf{c} / \mathrm{m}_{2 /} \mathrm{C}$ \\
$\Downarrow$ & \\
$\mathrm{w}_{2}:$ & $\mathbf{d} / \mathrm{m}_{3 /} \mathrm{C}$ \\
$\ldots$ & $\ldots$ \\
\hline & figure 6
\end{tabular}

To explain this figure: Individual essences are now given by inflexible properties, $\mathrm{S}_{\mathrm{i}}-$ originating from $m_{i}$ plus $C$ - and each of them can be said to individuate a possibile. So (5) is accommodated. We're under no pressure to deny (3) or (2), so we accommodate them too. Because we keep transitivity, the picture (like Williamson's and unlike Salmon's) doesn't need to grow horizontally. It is in the way the account accommodates (4) that makes a difference, as the following unfolds.

The modal space of inflexible-(EMOA) is the simplest one because it does with a unique chain of worlds with uniquely inhabited tables. This, in turn, makes it the account that best manages to accommodate the anti-haecceitist intuition underlying (4). In §2 we saw how Salmon motivates it. He also characterizes it; as the

\footnotetext{
22 Fine (2000) has argued independently that two letters can spatially coincide at some times. Even if his example is persuasive, Fine's letters are not yet a case of full spatio-temporal coincidence, as Bruce's letter comes into existence sooner than Bertha's. Also, Fine's two letters have different categorical features: their second words, for instance, are different. The Williamsonian denial of (3) is stronger than Fine's denial of Locke's thesis: It is committed to fully spatio-temporally coincident entities that do not differ at all in categorical properties either. Thanks to Matti Eklund and an anonymous referee for pressing me on this.
} 
"reductionist" intuition that objects are "nothing over and above" their matter and structure, in the sense that a complete accounting of what matter there is in a genuinely possible world, with its causal interconnections and exact configuration through time, atom for atom, quark for quark, must completely and uniquely determine whatever physical facts there are about each of the physical objects such as tables and ships present in the world, including such facts as that a particular hunk of matter $a^{\prime}$ constitutes a particular ship $a$ at time $t$. (Salmon 1982, 237)

On the Williamsoninan view, it is always many beings that supervene on facts about matter and structure. This is important. For even if it's always the same many beings that supervene on same facts, artefacts, on that view, must be something over and above structure and matter: for numerically distinct beings supervene on numerically identical such facts. Those distinctness facts are not grounded in the way the reductionist intuition above expects. Only inflexible-(EMOA) can strictly accommodate such intuition and thus aspire to maximal conservativeness.

This concludes my brief statement of the reasons for preferring the inflexible-(EMOA) account. That the statement can be brief is only due to it arriving after an in-depth exploration of the most salient rivals. On the basis of those explorations, I intend the reasons themselves to be recognized as strong, abductive reasons.

\section{A bad reason against inflexible-(EMOA)}

I shall conclude by undermining a reason against the current view: namely, that it requires an utterly false correspondingly-inflexible view in the temporal case.

Let us first see on what grounds one could think so. The persistence conditions through time for an artefact are also intuitively flexible: an artefact survives changes in material constitution through time. And flexible intuitions in the temporal case generate paradoxes too, like the Ship of Theseus Paradox. The fact that the main generator of temporal and modal paradoxes is a flexible intuition in both cases might make one think that the solutions to both sorts of paradoxes should be uniform: either we violate both intuitions or we violate none. ${ }^{23}$ If that is so, the inflexible-(EMOA) approach would need to go hand in hand with an inflexible view in the temporal case, according to which, table $a$ 's loss of one molecule at a given time would result in a different table. This would be bad news because-as I am ready to grant-the flexible intuition in the temporal case is close to non-negotiable.

Against this concern, I shall argue (i) that we would need to be given reasons for the uniform-solution desideratum, and (ii) that taking tables to be certain spatio-temporally extended entities suffices to accommodate the flexible intuition in the temporal case and is compatible with the inflexible-(EMOA) account that has been here abductively favoured. This would constitute further progress still in equilibrium.

The case of (i). The persistence conditions through time for an artefact, $x$, are not intuitively the same as what we might call 'the persistence conditions across worlds'. They are not because our underlying intuitions are not the same, despite both being flexible. Flexible intuitions in the temporal case are more flexible than flexible intuitions in the modal case. This can be seen by reflecting on figure 7 , where capital letters stand

${ }^{23}$ Williamson (1990) is a salient representative here. 
for pieces of matter, and $a$ and $b$ are distinct artefacts that would be constituted by a number-six in the example-of those pieces of matter:

\begin{tabular}{|c|c|c|c|c|c|c|c|c|}
\hline \multirow[b]{2}{*}{$w_{7}$} & \multirow[b]{2}{*}{$b$} & \multirow{2}{*}{$\begin{array}{c}\begin{array}{c}\text { original } \\
\text { matter }\end{array} \\
\text { GHIJKL }\end{array}$} & \multicolumn{6}{|c|}{ subsequent (non-original) matter through temporal change } \\
\hline & & & $\ldots$ & $\ldots$ & $\ldots$ & $\ldots$ & $\ldots$ & $\ldots$ \\
\hline$w_{6}$ & $b$ & GHIJKF & $\ldots$ & $\ldots$ & $\ldots$ & $\ldots$ & $\ldots$ & $\ldots$ \\
\hline$w_{5}$ & $b$ & GHIJEF & $\ldots$ & $\ldots$ & $\ldots$ & $\ldots$ & $\ldots$ & $\ldots$ \\
\hline$w_{4}$ & $a$ & GHIDEF & $\ldots$ & $\ldots$ & $\ldots$ & $\ldots$ & $\ldots$ & $\ldots$ \\
\hline$w_{3}$ & $a$ & GHCDEF & $\ldots$ & $\ldots$ & $\ldots$ & $\ldots$ & $\ldots$ & $\ldots$ \\
\hline$w_{2}$ & $a$ & GBCDEF & $\ldots$ & $\ldots$ & $\ldots$ & $\ldots$ & $\ldots$ & $\ldots$ \\
\hline \multirow[t]{3}{*}{$w_{1}$} & $a$ & ABCDEF & GBCDEF & GHCDEF & GHIDEF & GHIJEF & GHIJKF & GHIJKL \\
\hline & & $a$ & $a$ & $a$ & $a$ & $a$ & $a$ & $a$ \\
\hline & & $t_{1}$ & $t_{2}$ & $t_{3}$ & $t_{4}$ & $t_{5}$ & $t_{6}$ & $t_{7}$ \\
\hline
\end{tabular}

This table represents the intuitive fact that a sequence of (small) changes across possible worlds results in a different entity sooner than the same sequence of changes through time; that is, the intuitive range of tolerance is narrower in the modal case. To illustrate: we have lost $a$ in $\mathrm{w}_{5}$ because, according to the modal flexible intuition, $a$ cannot originate from a hunk of matter that, like GHIJEF, is too different from $a$ 's actual original matter: $\mathrm{ABCDEF}$. And we have not lost $a$ in $\mathrm{t}_{5}$ because, according to the temporal flexible intuition, $a$ can subsequently be constituted by GHIJEF in the actual world.

The intuitions are therefore not the same. Why, then, should a uniform-solution be a desideratum? At a minimum, the mere fact that the intuitions are not the same calls for reasons if we are to have it as a desideratum. For, once shown to be different intuitions, why should these two intuitions be accommodated or violated together? In addition, the prospects of finding a persuasive reason for such desideratum should be low if, as I shall next motivate, the independently abductively favoured inflexible-(EMOA) account is compatible with a view on what tables are that accommodates the (non-negotiable) temporal intuition.

The case of (ii). Provided-an assumption I shall not defend here-that reality is spatio-temporally extended, spatio-temporally extended portions of reality are possible referents of our singular concepts and singular terms. General concepts help us classify such portions. If one takes (certain) intuitions about artefacts as speaking of the semantics of our terms-as many would-such intuitions are to be taken as data when articulating the meaning of our terms. For instance, to accommodate the temporal flexible intuition, one must take the application and the co-application conditions for, for instance, 'table', to leave room for tables to survive changes in material constitution. ${ }^{24}$ And it suffices that one takes them to do so. Similarly, if one wants to accommodate the intuition that no two tables can ever spatially coincide, one must take the semantics of 'table' to rule that out. These two intuitions are mutually consistent and, together, they suggest that the application and co-application conditions for 'table' includes something along the following lines:

${ }^{24}$ I'm following Thomasson's (2009) here. 
(AC) being a maximal sequence of temporally continuous maximal spatially extended and contiguous table-shaped wholes.

Taking the (AC)-constraints on board, and assuming that (common sense) table $a$ from figure 7 came into existence at $t_{1}$ and ceased to exist at $t_{7}$, only the first of the following eight sequences is a portion of reality that can be correctly described as a table; the table that we've been calling ' $a$ '. The rest are proper parts of that table that do not satisfy the (AC)-conditions:

\begin{tabular}{|c|c|c|}
\hline \multirow{8}{*}{$\mathrm{w}_{1}$} & $\mathrm{P}_{1}$ & ABCDEF•GBCDEF•GHCDEF•GHIDEF•GHIJEF•GHIJKF•GHIJKL \\
\hline & $\mathrm{P}_{2}$ & GBCDEF•GHCDEF•GHIDEF•GHIJEF•GHIJKF•GHIJKL \\
\hline & $\mathrm{P}_{3}$ & $\mathrm{ABCDEF} \bullet \mathrm{BCDEF} \bullet \mathrm{GHCDEF} \bullet \mathrm{GHIDEF} \bullet$ \\
\hline & $\mathrm{P}_{4}$ & $\mathrm{ABCDEF} \bullet \mathbf{G B C D E F} \bullet \mathbf{G H C D E F}$ \\
\hline & $\mathrm{P}_{5}$ & ABCDEF•GBCDEF•GHCDEF•GHIDEF•GHIJEF•GHIJKF \\
\hline & $\mathrm{P}_{6}$ & GHIDEF•GHIJEF•GHIJKF•GHIJKL \\
\hline & $\mathrm{P}_{7}$ & 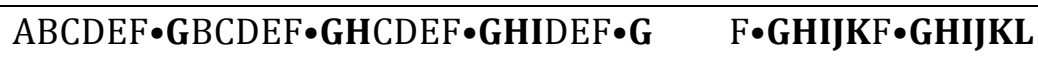 \\
\hline & $\mathrm{P}_{8}$ & BCDEF• BCDEF• HCDEF・ HIDEF• HIJEF• HIJKF• HIJKL \\
\hline & & $t_{3} t_{4}$ \\
\hline
\end{tabular}

Portion $\left(\mathrm{P}_{2}\right)$, for instance, is not a maximal sequence, for «ABCDEF» exists but is not part of $\left(\mathrm{P}_{2}\right)$. Nor is $\left(\mathrm{P}_{5}\right)$, for analogous reasons. Also, if $A$ is sufficiently small, «BCDEF» might still be table-shaped but it is not a maximal spatially extended and contiguous tableshaped whole; $A B C D E F$ would be maximal in this sense. Under this assumption, $\left(\mathrm{P}_{8}\right)$ is not a sequence of maximal spatially extended and contiguous table-shaped wholes, so such portion of reality is also only a part of a table.

Now, if tables are this sort of spatio-temporally extended portions of reality, they can survive change through time, as $a$ does in figure 7. This view is compatible with a variety of modal views about tables: can two different (AC)-sequences-i.e., different portions of reality-in different worlds be the same table? How one answers this question (and related ones) will reflect what intuitive possibilities for tables one wants to accommodate. For instance, answering "Yes, provided one is a proper initial segment of the other" would basically only allow the tables' duration to be contingent; answering "Yes, provided the first element in each sequence is the same" would imply inflexible(EMOA) but allow for different material futures of the same table; answering "Yes, provided the first element in each sequence overlaps enough with the other" would be even more liberal in implying flexible-(EMOA)". Each of these answers would need to be scrutinized in a way similar to what has been done in this paper with the thesis of essentiality of origins, and it is to be expected that some will have higher costs than others. ${ }^{25}$

For current purposes, it suffices to conclude by saying that, the more liberal we are with our answers, the more we are distancing ourselves from the reductionist intuition

\footnotetext{
25 Other relevant questions, for the temporal case, include whether different sequences in the same world could be the same table (as it would intuitively happen with a dismantled and reassembled ship), or whether the same sequence in the same world at different intervals of time would be the same table. The (AC) application conditions leaves all these matters open, and is, as such, compatible with a number of solutions to the temporal paradoxes.
} 
that objects are "nothing over and above" their matter and structure. If, apart from ontological neatness-which contributed to favouring inflexible-(EMOA)-the reductionist intuition is also something we want to try to accommodate at its best, then, the answer to be given to the question above is the stringent: "No, never". Such answer implies inflexible-(EMOA), and makes material constitution at each time-not just at the original time-essential to tables. I feel some sympathy for such reductionist view of artefacts. Importantly, however, despite being quite a rigid essentialist position, it is not as rigid as to disallow continuance through (temporal) change. Even more importantly, it is not necessitated by inflexible-(EMOA); it's only very congenial to it. ${ }^{26}$

\section{References}

Bottani, G. and Carrara, M. (Eds.). 2002. Individuals, Essence and Identity, Themes of Analytic Metaphysics. The Netherlands: Kluwer Academic Publishers.

Chalmers, D., Manley, D., and Wasserman, R. (Eds.). 2009. Metametaphysics. Oxford: Clarendon Press.

Fine, K. 2000. A Counter-example to Locke's Thesis. Monist 83(3): 357-61.

Forbes, G. 2002. Origins and Identities. In Bottani, G. and Carrara, M. 2002, pp. 319-431. The Netherlands: Kluwer Academic Publishers.

Hawthorne, J. and Gendler, T. 2000. Origin Essentialism: The Arguments Reconsidered. Mind 109(434): 285-298.

Lewis, D. 1986. On the Plurality of Worlds. Oxford: Basil Blackwell.

Mackie, P. 2006. How Things Might Have Been: Individuals, Kinds, and Essential Properties. Oxford: Oxford University Press.

Peacocke, C. 2002. Principles for Possibilia. Noûs 36(3): 486-508.

Robertson, T. 1998. Possibilities and the Arguments for Origin Essentialism. Mind 107(428): 729-749.

- 2000. Essentialism: Origins and Order. Mind 109(434): 299-307

Roca-Royes, S. 2006. Peacocke's Principle-Based Account: Flexibility of Origin plus S4. Erkenntnis 65(3): 405-426.

Salmon, N. 1982. Reference and Essence. Basil Blackwell, Oxford.

- 1989. The Logic of What Might Have Been. The Philosophical Review 98(1): 3-34.

Thomasson, A. 2009. Answerable and Unanswerable Questions. In Metametaphysics,

Chalmers, D., Manley, D., and Wasserman, R.(Eds.). Oxford: Clarendon Press.

Williamson, T. 1990. Identity and Discrimination. Oxford: Basil Blackwell.

\footnotetext{
${ }^{26}$ Remote ancestors of this paper were presented in 2005 at the VII Taller d'Investigació en Filosofia (València), the Logos Graduate Group (Barcelona) and the Arché Modality Seminar (St. Andrews). A more recent version was presented in 2012 at a PERSP Workshop (Barcelona) and the Reality Making Conference (Nottingham), from where the present volume emerges. I'd like to thank the audiences on those occasions with a special mention to Oscar Cabaco, Stephan Torre and Naomi Thompson, for their valuable and penetrating comments in, respectively, the first, fourth and fifth of those events. I'd like to thank also Manuel García-Carpintero, Bob Hale, Mark Jago, Dan López de Sa, Harold Noonan, Penelope Mackie and Tim Williamson for helpful exchanges and discussions. Finally, I'd like to thank the two referees for this volume, whose comments have helped me improve the paper too.
} 